\title{
The TRPV4-AKT axis promotes oral squamous cell carcinoma cell proliferation via CaMKII activation
}

\author{
Shinsuke Fujii $\mathbb{D}^{1} \cdot$ Yudai Tajiri $^{1,2} \cdot$ Kana Hasegawa $^{1} \cdot$ Shinji Matsumoto ${ }^{3} \cdot$ Reiko U. Yoshimoto $^{1,4,5} \cdot$ Hiroko Wada $^{1}$. \\ Shosei Kishida ${ }^{6} \cdot$ Mizuho A. Kido $^{4} \cdot$ Hiromasa Yoshikawa $^{2} \cdot$ Satoru Ozeki ${ }^{2} \cdot$ Tamotsu Kiyoshima $^{1}$
}

Received: 13 August 2019 / Revised: 22 November 2019 / Accepted: 30 November 2019 / Published online: 19 December 2019

(c) The Author(s), under exclusive licence to United States and Canadian Academy of Pathology 2019

\begin{abstract}
Most human malignant tumor cells arise from epithelial tissues, which show distinctive characteristics, such as polarization, cell-to-cell contact between neighboring cells, and anchoring to a basement membrane. When tumor cells invaginate into the stroma, the cells are exposed to extracellular environments, including the extracellular matrix (ECM). Increased ECM stiffness has been reported to promote cellular biological activities, such as excessive cellular growth and enhanced migration capability. Therefore, tumorous ECM stiffness is not only an important clinical tumor feature but also plays a pivotal role in tumor cell behavior. Transient receptor potential vanilloid 4 (TRPV4), a $\mathrm{Ca}^{2+}$-permeable nonselective cation channel, has been reported to be mechano-sensitive and to regulate tumorigenesis, but the underlying molecular mechanism in tumorigenesis remains unclear. The function of TRPV4 in oral squamous cell carcinoma (OSCC) is also unknown. The current study was conducted to investigate whether or not TRPV4 might be involved in OSCC tumorigenesis. TRPV4 mRNA levels were elevated in OSCC cell lines compared with normal oral epithelial cells, and its expression was required for TRPV4 agonist-dependent $\mathrm{Ca}^{2+}$ entry. TRPV4-depleted tumor cells exhibited decreased proliferation capabilities in three-dimensional culture but not in a lowattachment plastic dish. A xenograft tumor model demonstrated that TRPV4 expression was involved in cancer cell proliferation in vivo. Furthermore, loss-of-function experiments using siRNA or an inhibitor revealed that the TRPV4 expression was required for CaMKII-mediated AKT activation. Immunohistochemical analyses of tissue specimens obtained from 36 OSCC patients showed that TRPV4 was weakly observed in non-tumor regions but was strongly expressed in tumor lesions at high frequencies where phosphorylated AKT expression was frequently detected. These results suggest that the TRPV4/CaMKII/AKT axis, which might be activated by extracellular environments, promotes OSCC tumor cell growth.
\end{abstract}

Supplementary information The online version of this article (https:// doi.org/10.1038/s41374-019-0357-z) contains supplementary material, which is available to authorized users.

Shinsuke Fujii

sfujii@dent.kyushu-u.ac.jp

1 Laboratory of Oral Pathology, Division of Maxillofacial Diagnostic and Surgical Sciences, Faculty of Dental Science, Kyushu University, 3-1-1 Maidashi, Higashi-ku, Fukuoka 8128582, Japan

2 Department of Dentistry and Oral Surgery, Clinical Research Institute, National Hospital Organization Kyushu Medical Center, 1-8-1 Jigyohama, Chuo-ku, Fukuoka 810-8563, Japan

3 Department of Molecular Biology and Biochemistry, Graduate School of Medicine, Osaka University, 2-2 Yamadaoka, Suita 5650871, Japan

\section{Introduction}

Oral squamous cell carcinoma (OSCC) arising from the mucosal epithelium accounts for more than $90 \%$ of oral cancers [1]. Stiffness, redness, erosion, ulcer, and pain are important clinical features of OSCC. Oral cancer, when

4 Department of Anatomy and Physiology, Division of Histology and Neuroanatomy, Faculty of Medicine, Saga University, 5-1-1 Nabeshima, Saga 849-8501, Japan

5 Department of Periodontology, Division of Oral Rehabilitation, Faculty of Dental Science, Kyushu University, 3-1-1 Maidashi, Higashi-ku, Fukuoka 812-8582, Japan

6 Department of Biochemistry and Genetics, Kagoshima University Graduate School of Medical and Dental Sciences, 8-35-1 Sakuragaoka, Kagoshima 890-8544, Japan 
oropharyngeal sites are included, is the sixth-most common cancer in the world [2]. The 5-year survival rate in the early stages is $80-90 \%$, while that in the late stages is only $20-30 \%$ [3, 4]. Improving results of cancer therapy will require diagnosing tumors in the early stages and treating the tumorous lesions with advanced combination treatments, such as surgical resection, radiotherapy and/or chemotherapy.

Both non-tumor and tumor cells are surrounded by extracellular environments, which includes neighboring cells and the extracellular matrix (ECM). The ECM provides cells with mechanical cues to influence diverse biological process [5]. Since matrix stiffening is a prominent hallmark of a tumor microenvironment clinically, its role in tumorigenesis has received intensive investigation. For instance, studies using mouse models for cancer research have shown that an increase in tumorous ECM stiffness can drive tumor progression through the activation of intracellular signaling, such as $\beta 1$ integrin-FAK signaling and RHOA-AKT-p300 signaling in breast cancer and liver cancer, respectively $[6,7]$. In addition, previous studies have shown that novel signaling molecules, such as ion channels and the Hippo pathway, respond to the extracellular environment and control cellular activities $[8,9]$. However, neither the biological function of extracellular environments nor the effect of the above molecules on OSCC tumorigenesis is well understood.

Transient receptor potential vanilloid 4 (TRPV4), which is a family of $\mathrm{Ca}^{2+}$-permeable nonselective cation channels [10], has been reported to be mechano- [11, 12], thermo- [13], and osmo-sensitive [14]. Recently, it was shown that TRPV4 promotes tumorigenesis in gastric cancer $[15,16]$ and hepatocellular carcinoma (HCC) [17], but the molecular mechanism underlying the involvement of TRPV4 in tumorigenesis remains unclear. Furthermore, whether or not TRPV4 signaling is involved in OSCC tumorigenesis, such as proliferation and migration, is also unclear. Herein, we investigated the expression of TRPV4 in OSCC cell lines and pathological specimens and explored its role in controlling OSCC cellular growth in vitro and in vivo.

\section{Materials and methods}

\section{Cell lines and reagents}

Human OSCC cell lines SAS, HSC-2, HSC-3, HSC-4 (Japanese Cancer Research Resources Bank) and SQUU-B [18], and human normal oral epithelial cells MOE1a [19] were used in this study. Lenti- $X^{\mathrm{TM}} 293 \mathrm{~T}$ (X293T) cells were purchased from Takara Bio Inc. (Shiga, Japan). HSC-2, HSC3 and HSC-4 were maintained in $\alpha$-MEM (Invitrogen,
Carlsbad, CA, USA) supplemented with $10 \%$ fetal bovine serum (FBS) (Invitrogen). SQUU-B was maintained in DMEM/F12 (Invitrogen) supplemented with $10 \%$ FBS. MOE1a was maintained in Defined Keratinocyte-SFM (Invitrogen). SAS and X293T were maintained in D-MEM (Invitrogen) supplemented with 10\% FBS.

Anti-TRPV4 polyclonal antibody was generated in guinea pigs by immunization with synthetic peptides corresponding to amino acid residues ( $\mathrm{N}$ terminus-CDGHQQGYAPKW RTDDAPL-C terminus) of mouse TRPV4 [20]. Antiphospho-AKT (4060S), anti-pan-AKT (4691S), antiphospho-CaMKII (12716S), and anti-pan-CaMKII (pan) (3362S) (for western blotting and immunohistochemistry) antibodies were obtained from Cell Signaling Technology (Beverly, MA, USA). Anti-Ki-67 (ab15580) (for immunofluorescence and immunohistochemistry) antibody was from Abcam (Cambridge, UK). Anti- $\beta$-actin (A5441) (for western blotting) antibody was from Sigma-Aldrich (Steinheim, Germany). Phalloidin was from Invitrogen. GSK1016790A, BAPTA-AM and EGTA were from FUJIFILM Wako Pure Chemical Corporation (Osaka, Japan). GSK2193874 and Arcyriaflavin A were from TOCRIS Bioscience (Bristol, UK). $\mathrm{Ca}^{2+} /$ Calmodulin-Dependent Protein Kinase II (CaMKII) Inhibitor XII and AKT inhibitor VIII were from Merck Millipore (Tokyo, Japan).

\section{Knockdown of protein expression by siRNA and quantitative RT-PCR}

The effects of protein knockdown by siRNA were analyzed as previously described [21, 22]. Briefly, siRNAs (final conc. 20 $\mathrm{nM})$ were transfected into HSC-4 cells using Lipofectamine RNAiMAX (Invitrogen). The following target sequences were used: randomized control, 5'-CAGTCGCGTTTG CGACTGG-3', human TRPV4 \#1, 5'-GCTTCTCTGCCCA CTCATT- $3^{\prime}$ and human TRPV4 \#2, 5'-GCTCCTATGGA GTCACATA- $3^{\prime}$. The transfected cells were then used for experiments conducted at $48 \mathrm{~h}$ post-transfection.

Quantitative RT-PCR was performed as described previously [22]. Forward and reverse primers were as follows: human TRPV4 (targeting open reading frame region), 5'-GA CGGGGACCTATAGCATCA-3' and 5'-AACAGGTCCA GGAGGAAGGT-3'; human TRPV4 (targeting 3'-untranslated region: 3'-UTR), 5'-TTCTAGTCCAGCCGCATTT C-3' and 5'-CGTTGGCTTATGTGACTCCA-3'; human G APDH, 5'-GCACCGTCAAGGCTGAGAAC-3' and 5'- TG GTGAAGACGCCAGTGGA-3'.

\section{Plasmid construction and infection using lentivirus harboring a CDNA or ShRNA}

The human TRPV4 plasmid was constructed using pcDNA3.1/ human TRPV4 [23], which was kindly gifted by Prof. 
M. Tominaga (Okazaki Institute for Integrative Bioscience (National Institute for Physiological Sciences), Okazaki, Japan). Lentiviral vector was constructed by subcloning human TRPV4 cDNA into CSII-CMV-MCS-IRES2-Bsd, which was kindly provided by Dr H. Miyoshi (RIKEN BioResource Center, Ibaraki, Japan) [24]. To construct a lentiviral vector harboring shRNA, a DNA fragment containing the $\mathrm{H} 1$ promoter and shRNA was cloned into CSRfA-EVBsd using Gateway technology (Invitrogen). Target sequence is 5'- GCTTCTCTGCCCACTCATT-3'. The vectors were then transfected along with the packaging vectors, pCAG-HIV-gp and pCMV-VSV-G-RSV-Rev, into X293T cells using the Lipofectamine LTX reagent (Invitrogen) to generate lentiviruses.

To generate HSC- 4 cells that stably express TRPV4 or TRPV4 shRNA, parental cells $\left(5 \times 10^{4}\right.$ cells/well in a 12 well plate) were treated with lentivirus and $10 \mu \mathrm{g} / \mathrm{ml}$ polybrene. The cells were then centrifuged at $1080 \times g$ for $1 \mathrm{~h}$, and incubated for another $24 \mathrm{~h}$. The cells that demonstrated stable expression of TRPV4 or TRPV4 shRNA, were selected and maintained in culture medium containing $5 \mu \mathrm{g} /$ ml Blasticidin S (FUJIFILM Wako) [25, 26].

\section{Intracellular calcium measurement}

To examine agonist-dependent $\mathrm{Ca}^{2+}$ influx, cells were loaded with Calcium Kit-Fluo-4 AM (FUJIFILM Wako) for $1 \mathrm{~h}$ at $37^{\circ} \mathrm{C}$ according to the manufacturer's instructions. The measurements were performed with FlexStation 3 microplate reader (Molecular Devices, Tokyo, Japan) using the 'Flex' read mode, and images at $485 \mathrm{~nm}$ excitation/525 nm emission were collected every $2 \mathrm{~s}$. Fluorescence measurements were taken for $5 \mathrm{~min}$ before, during, and after compound addition. To examine intracellular $\mathrm{Ca}^{2+}$ in the cells without the agonist treatment, cells were loaded with $8 \mu \mathrm{M}$ Oregon Green 488 BAPTA-1 AM (OGB-1) (Invitrogen) for $1 \mathrm{~h} \mathrm{at} 37^{\circ} \mathrm{C}$ according to the manufacturer's instructions. The samples were viewed and analyzed with confocal microscope $\mathrm{C} 2 \mathrm{si}^{+}$ (NIKON, Tokyo, Japan).

\section{Immunofluorescence staining}

HSC-4 cells were fixed for $30 \mathrm{~min}$ at room temperature (RT) in 4\% paraformaldehyde (PFA) buffered by phosphate-buffered saline (PBS), and then permeabilized in PBS containing $0.5 \%(\mathrm{w} / \mathrm{v})$ Triton X-100 and $40 \mathrm{mg} / \mathrm{ml}$ BSA (Wako) for $30 \mathrm{~min}$. The cells were incubated with primary antibodies (used at 1:200) for $3 \mathrm{~h}$ at RT and then with secondary antibodies for $3 \mathrm{~h}$ at RT in accordance with the manufacturer's protocols (Jackson ImmunoResearch Inc., West Grove, PA, USA). The samples were viewed and analyzed with confocal microscope $\mathrm{C} 2 \mathrm{si}^{+}$ (NIKON).

\section{Xenograft tumor assay}

Five-week-old male BALB/cAnNCrj-nu nude mice (Charles River Laboratory Japan Inc, Osaka, Japan) were anesthetized with a combination of medetomidine $(0.3 \mathrm{mg} / \mathrm{kg}$ body weight $)$ and midazolam $(4 \mathrm{mg} / \mathrm{kg})$. The mice then received a dorsal subcutaneous injection of HSC-4 $\left(5 \times 10^{7}\right.$ cells $)$ cells suspended in $100 \mu$ PBS [27]. The nude mice were then sacrificed at 14 days after transplantation, and the areas containing transplanted cells were measured, weighed, and processed for immunohistochemical analyses. Tumor volumes were calculated using the following formula: (major axis $) \times($ minor axis $) \times($ minor axis $) \times 0.5$ [27]. All protocols used for all animal experiments in this study were approved by the Animal Research Committee of Kyushu University, Japan (No. A29-279-1).

\section{Immunohistochemical study of xenograft tumors}

Xenograft tumors derived from HSC-4 cells were fixed in 4\% PFA and processed for paraffin embedding. Specimens for examination were sectioned at $5 \mu \mathrm{m}$ thickness and carried out immunohistochemical staining for Ki-67 and phospho-AKT.

Antigen retrieval for staining was done using a decloaking chamber (Biocare Medical, Walnat Creek, CA, USA). The endogenous peroxide activity was then eliminated by treatment with $1 \%$ hydrogen peroxide in methanol for $30 \mathrm{~min}$. Nonspecific protein binding was blocked with $10 \%$ goat serum (Nichirei, Tokyo, Japan) for $30 \mathrm{~min}$, and then the sections were reacted with each primary antibody (used at 1:300 for Ki-67, used at 1:100 for phospho-AKT) at $4{ }^{\circ} \mathrm{C}$ overnight. The sections were incubated with secondary antibody (Histofine Simple Stain MAX PO, Nichirei) for $1 \mathrm{~h}$ at RT. The immunoreactivity was visualized with a solution of 3,3'-diaminobenzidine and $<0.1 \%$ hydrogen peroxide (DAB substrate solution, Nichirei). Subsequently, the sections were counterstained with hematoxylin and the numbers of Ki-67-positive cells or hematoxylin-stained cells were counted [27].

\section{Patients and immunohistochemistry}

A total of 36 patients with ages ranging from 37 to 94 years (median, 72 years) with primary OSCC diagnosed at the Department of Dentistry and Oral Surgery, Kyushu Medical center, Japan, from January 2013 to December 2018 were examined in this study. Patients' informed consent and the approval of the local ethics committee were given (\#17c006). Following the initial biopsy, all specimens were fixed in $10 \%$ $(\mathrm{v} / \mathrm{v})$ formalin and embedded in paraffin blocks. Subsequently, the paraffin-embedded specimens were sliced into 4- $\mu$ m-thick sections, stained with hematoxylin-eosin (HE), and examined by three experienced pathologists to confirm the diagnoses 
Table 1 Relationship between TRPV4 intensity and clinicopathological characteristics of OSCC cases.

\begin{tabular}{|c|c|c|c|c|c|c|}
\hline & & \multicolumn{4}{|c|}{ TRPV4 expression } & \multirow[t]{2}{*}{$P$ value } \\
\hline & & - & Weak & Moderate & Strong & \\
\hline \multicolumn{7}{|c|}{ Clinical T stage } \\
\hline $\mathrm{T} 1$ & 6 & 2 & 2 & 2 & 0 & \\
\hline $\mathrm{T} 2$ & 6 & 2 & 2 & 2 & 0 & \\
\hline T3 & 14 & 5 & 3 & 4 & 2 & \\
\hline $\mathrm{T} 4$ & 10 & 5 & 5 & 0 & 0 & N.S. ${ }^{\mathrm{a}}$ \\
\hline \multicolumn{7}{|c|}{ Histologic grade } \\
\hline Well & 29 & 10 & 12 & 6 & 1 & \\
\hline Moderately & 5 & 2 & 0 & 2 & 1 & \\
\hline Poorly & 2 & 2 & 0 & 0 & 0 & N.S. ${ }^{\text {a }}$ \\
\hline \multicolumn{7}{|c|}{ Lymph node metastasis } \\
\hline Positive & 9 & 2 & 6 & 0 & 1 & \\
\hline Negative & 27 & 12 & 6 & 8 & 1 & N.S. ${ }^{a}$ \\
\hline
\end{tabular}

Clinical T stage; $T 1$ Tumour $2 \mathrm{~cm}$ or less in greatest dimension and $5 \mathrm{~mm}$ or less depth of invasion, T2 Tumour $2 \mathrm{~cm}$ or less in greatest dimension and more than $5 \mathrm{~mm}$ depth of invasion or Tumour more than $2 \mathrm{~cm}$ but not more than $4 \mathrm{~cm}$ in greatest dimension and depth of invasion no more than $10 \mathrm{~mm}, T 3$ Tumour more than $2 \mathrm{~cm}$ but not more than $4 \mathrm{~cm}$ in greatest dimension and depth of invasion more than $10 \mathrm{~mm}$ or Tumour more than $4 \mathrm{~cm}$ in greatest dimension and not more than $10 \mathrm{~mm}$ depth of invasion, T4a (Lip), Tumour invades through cortical bone, inferior alveolar nerve, floor of mouth, or skin (of the chin or the nose), T4a (Oral cavity), Tumour more than $4 \mathrm{~cm}$ in greatest dimension and more than $10 \mathrm{~mm}$ depth of invasion or tumour invades through the cortical bone of the mandible or maxilla or involves the maxillary sinus, or invades the skin of the face, T4b (Lip and oral cavity), Tumour invades masticator space, pterygoid plates, or skull base, or encases internal carotid artery. Histologic grade (WHO); Grade 1 well differentiated, Grade 2 moderately differentiated, Grade 3 poorly differentiated

${ }^{a}$ Statistical analyses were performed by Fisher's exact test

and the histological grades. The histological grade in the OSCC was assessed according to the World Health Organization (WHO) classification [1]. The tumor extent and the clinical stages were evaluated according to the TNM classification established by the American Joint Committee on Cancer and the International Union Against Cancer (UICC) [28]. The medical records were reviewed to collect information on the clinical characteristics. The clinicopathological data of the patients with OSCC are presented in Table 1.

Immunohistochemical staining was performed on $4-\mu \mathrm{m}-$ thick paraffin sections. Antigen retrieval, elimination of the endogenous peroxide activity, and blocking were carried out as previously mentioned. Then the sections were reacted with each primary antibody (used at $2 \mu \mathrm{g} / \mathrm{ml}$ for TRPV4, used at 1:100 for phospho-AKT) at $4{ }^{\circ} \mathrm{C}$ overnight. The sections were incubated with secondary antibody (Jackson ImmunoResearch Inc. for TRPV4, Histofine Simple Stain MAX PO for phospho-AKT) for $1 \mathrm{~h}$ at RT and peroxidaseconjugated streptavidin (for TRPV4) for $1 \mathrm{~h}$ at RT. The immunoreactivity was visualized with a solution of $\mathrm{DAB}$ substrate solution. Subsequently, the sections were counterstained with hematoxylin [22, 29]. When the total area of a tumor lesion showed $>20 \%$ staining, the results were defined as TRPV4 or phospho-AKT positive.

\section{Statistical analysis}

Statistical analyses were performed using JMP Pro 11 software, and using Fisher's exact test for Table 1, Analysis of Variance (ANOVA) with turkey, Wilcoxon signed-rank test and Student's $t$ test for other experiments. $P$ values of $<0.01$ were considered statistically significant.

\section{Additional assays}

Cell proliferation and migration assays were performed as previously described [26]. Western blotting data were representative of at least three independent experiments.

\section{Results}

\section{TRPV4 expression in oral squamous cell carcinoma cells}

To examine TRPV4 mRNA expression in human OSCC cells, five OSCC cell lines were used for a comparison with its expression in human oral squamous epithelium-derived normal oral epithelial cells, MOE1a (Fig. 1a). All OSCC cell lines expressed TRPV4 mRNA higher than MOE1a cells. Among the OSCC cell lines, HSC-4 and SAS highly expressed TRPV4 mRNA (Fig. 1a). Treatment with GSK1016790A, a selective TRPV4 agonist, increased the $\mathrm{Ca}^{2+}$ influx in a dosedependent manner in HSC-4 cells (Fig. 1b). In contrast, GSK1016790A treatment increased the $\mathrm{Ca}^{2+}$ influx in SAS cells lower than that in HSC-4 cells (Supplementary Fig. 1a), suggesting that the $\mathrm{Ca}^{2+}$ influx may depend on TRPV4 expression in the cells. To clarify the role of TRPV4 in HSC-4 and SAS cells, TRPV4 was knocked down by two different siRNAs (Fig. 1c and Supplementary Fig. 1b). TRPV4 knockdown decreased the GSK1016790A-dependent $\mathrm{Ca}^{2+}$ influx as well as intracellular $\mathrm{Ca}^{2+}$ without GSK1016790A treatment in OSCC cells (Fig. 1d, e and Supplementary Fig. 1c, d). These results suggest that endogenous TRPV4 expression may regulate the $\mathrm{Ca}^{2+}$ entry in OSCC cells.

\section{TRPV4 expression is required for cell proliferation and migration through CaMKII-mediated AKT activation}

As TRPV4 was shown to be capable of regulating tumorigenesis in gastric cancer [15, 16] and HCC [17], we 

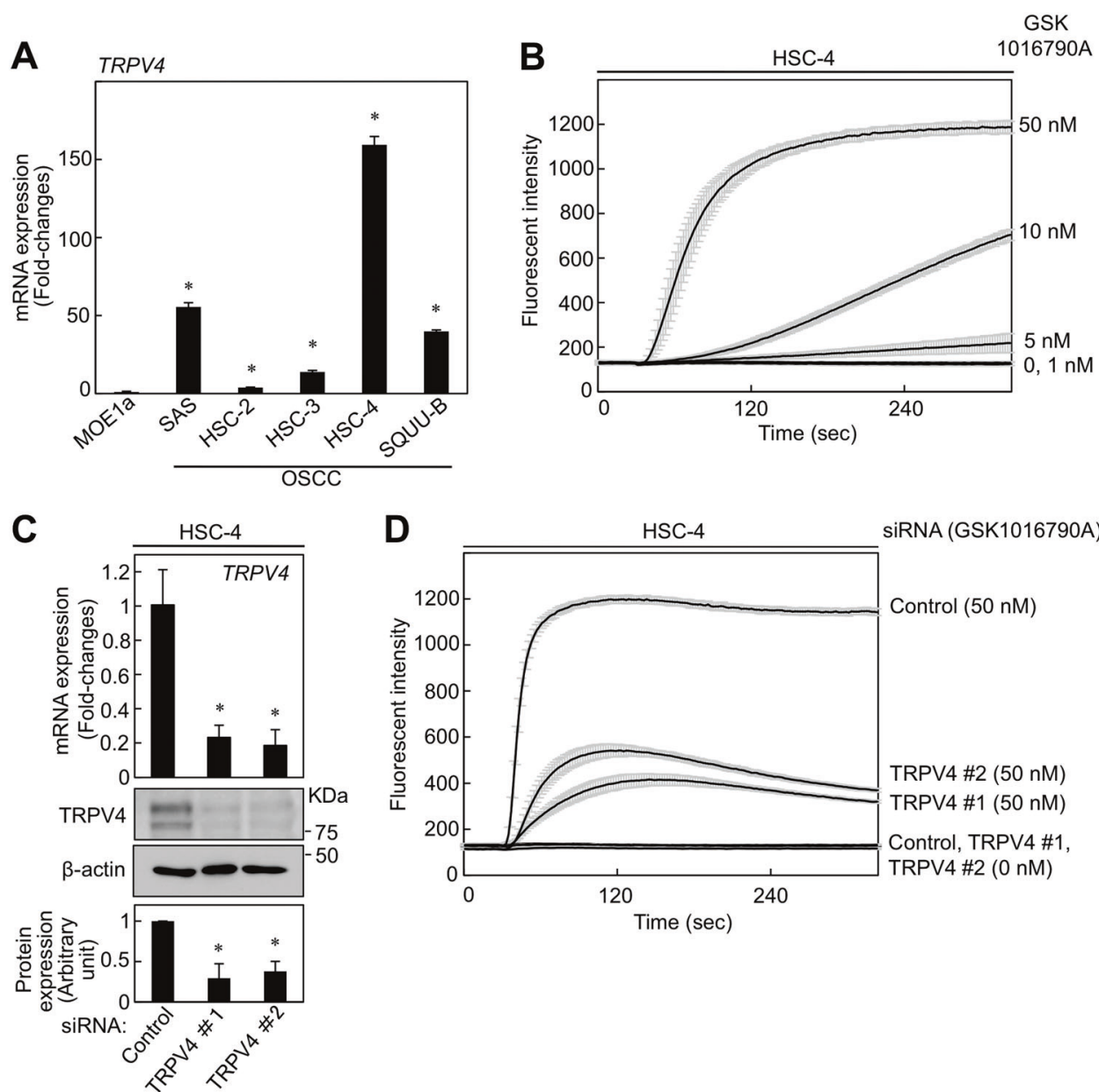

E

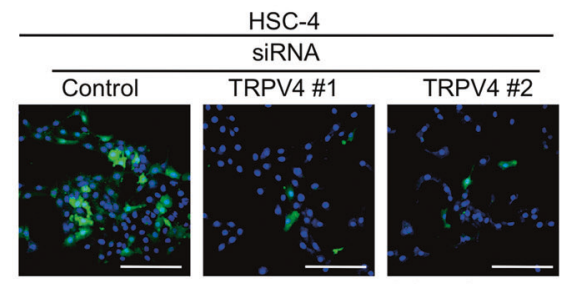

OGB-1/Nucleus

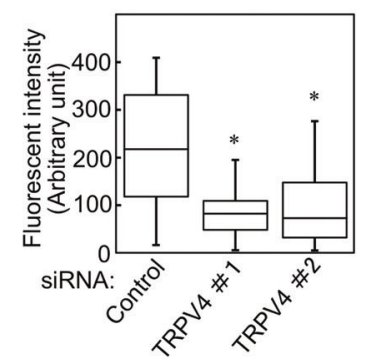

Fig. 1 TRPV4 expression in oral squamous cell carcinoma cells. a TRPV4 mRNA levels were measured in OSCC cell lines (SAS, HSC-2, HSC-3, HSC-4, SQUU-B) using quantitative RT-PCR. Relative levels of TRPV4 mRNA expression were normalized to $G A P D H$ and expressed as fold-changes compared with expression in MOE1a cells. b Fluo-4-AM-loaded HSC-4 cells were cultured in 96-well plates, and were exposed without or with $1,5,10$, and $50 \mathrm{nM}$ GSK1016790A. Then, intracellular $\mathrm{Ca}^{2+}$ influx was measured. c HSC4 cells were transfected with control or two different TRPV4 siRNAs for $48 \mathrm{~h}$, and TRPV4 mRNA levels were measured by quantitative RTPCR. Relative TRPV4 mRNA levels were normalized by GAPDH and expressed as fold-changes compared with levels in control siRNA transfected cells. Cell lysates were probed with anti-TRPV4 and anti-

examined the effect of TRPV4 on cell proliferation and migration in OSCC cells. TRPV4 knockdown decreased the cell proliferation capability and ratio of $\mathrm{Ki}-67$-positive $\beta$-actin antibodies. Band intensities were quantified using NIH image software and ratio of TRPV4/ $\beta$-actin was expressed as fold-changes compared with control cells. d HSC-4 cells were transfected with control or two different TRPV4 siRNAs for $48 \mathrm{~h}$ and Fluo-4-AMloaded cells were cultured in 96-well plates. The cells were exposed without or with $50 \mathrm{nM}$ GSK1016790A, and intracellular $\mathrm{Ca}^{2+}$ influx was measured. e HSC-4 cells were transfected with control or two different TRPV4 siRNAs for $48 \mathrm{~h}$ and cells were loaded with $8 \mu \mathrm{M}$ OGB- 1 for last $1 \mathrm{~h}$. Then, the cells were stained Hoechst 33342 and OGB-1-positive fluorescent intensity was measured. $\times 200$ magnification, scale bars, $50 \mu \mathrm{m}$. Results are shown as means \pm s.d. of three independent experiments. $* P<0.01$.

proliferating cells in HSC-4 and SAS cells (Fig. 2a, b and Supplementary Fig. 2a). In addition, GSK2193874, a selective TRPV4 antagonist, also suppressed cellular growth in a 
A
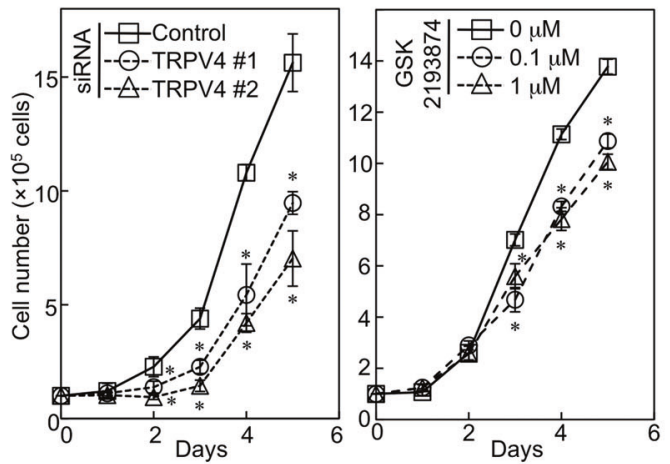

B

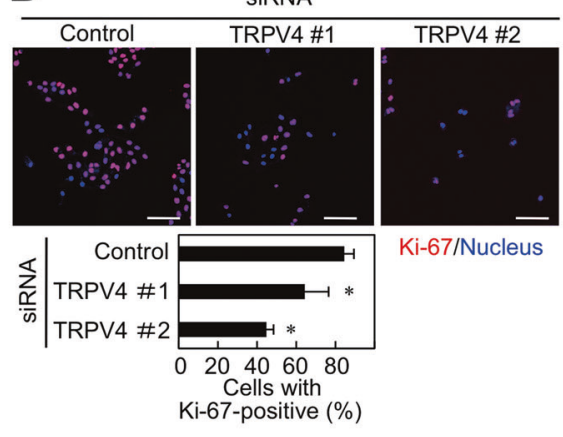

C

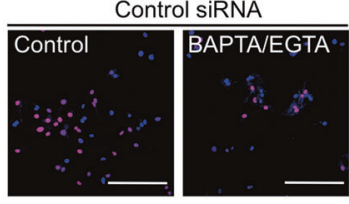

TRPV4 \#1 siRNA
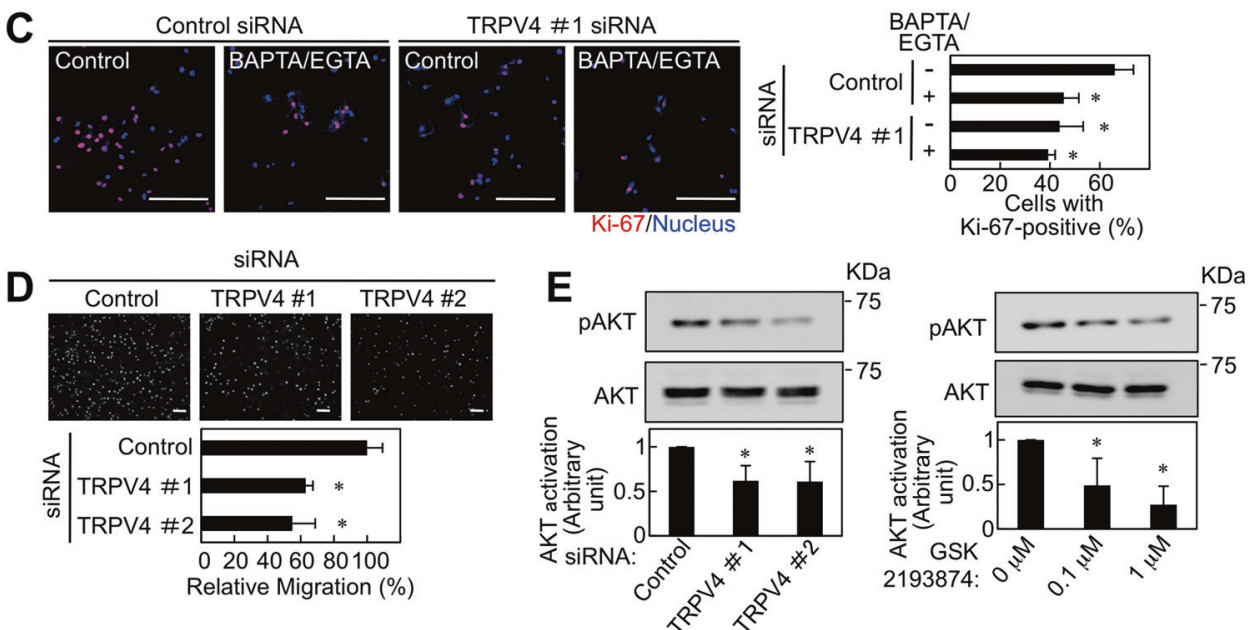

$\mathbf{F}$

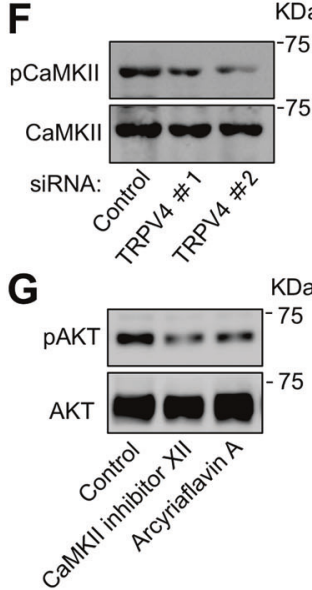

H
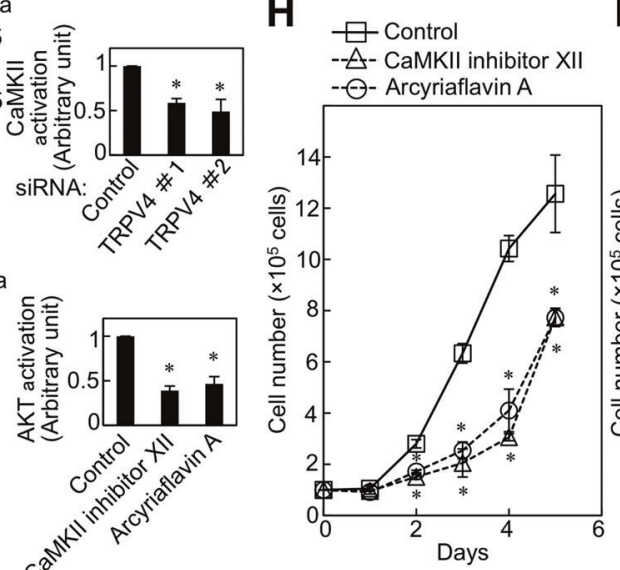

I

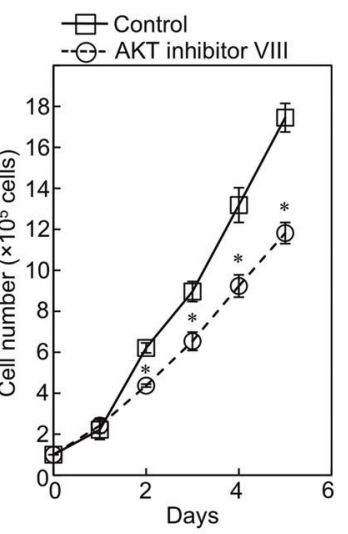

dose-dependent manner (Fig. 2a, right). GSK2193874 treatment indeed decreased the GSK1016790A-dependent $\mathrm{Ca}^{2+}$ influx in a dose-dependent manner in HSC-4 cells (Supplementary Fig. 2b). Both TRPV4 knockdown and depletion of intracellular and extracellular calcium using calcium chelators (BAPTA/EGTA) decreased ratio of Ki-67-positive proliferating cells (Fig. 2c and Supplementary Fig. 2c). In addition, ratio of Ki-67positive proliferating cells in TRPV4 knockdown plus
BAPTA/EGTA treatment was comparable to that of TRPV4 knockdown or BAPTA/EGTA treatment, indicating that endogenous TRPV4 expression is sufficient to regulate the cell proliferative capability through $\mathrm{Ca}^{2+}$ influx. TRPV4 knockdown also reduced the migration of HSC-4 and SAS cells (Fig. 2d and Supplementary Fig. 2d). These data suggest that the endogenous TRPV4 expression may promote cell proliferation and migration in OSCC cells. 
Fig. 2 TRPV4 expression regulates cell proliferation and migration. a HSC-4 cells were transfected with control or two different TRPV4 siRNAs (left panel), or were cultured without or with 0.1 and $1 \mu \mathrm{M}$ GSK2193874 (right panel) in the presence of 5\% FBS for the indicated numbers of days, and cell numbers were counted. b HSC-4 cells were transfected with control or two different TRPV4 siRNAs for $48 \mathrm{~h}$. The cells were stained with anti-Ki-67 antibody and Hoechst 33342, and then Ki-67-positive cells and Hoechst 33342-stained cells were counted, respectively. Results are expressed as the percentage of Ki-67-positive cells compared with total Hoechst 33342-stained cells. $\times 200$ magnification, scale bars, $100 \mu \mathrm{m}$. c HSC-4 cells were transfected with control or TRPV4 \#1 siRNA for $48 \mathrm{~h}$, and were cultured without or with $10 \mu \mathrm{M}$ BAPTA and $1 \mathrm{mM}$ EGTA for last $8 \mathrm{~h}$. The cells were stained with anti-Ki-67 antibody and Hoechst 33342, and then Ki-67-positive cells and Hoechst 33342-stained cells were counted, respectively. Results are expressed as the percentage of Ki-67-positive cells compared with total Hoechst 33342-stained cells. $\times 200$ magnification, scale bars, $50 \mu \mathrm{m}$. d HSC-4 cells were transfected with control or two different TRPV4 siRNAs, and then the cells were placed in Transwell chamber for the migration assay. Migration activities are expressed as the percentage of control cells. $\times 100$ magnification, scale bars, $200 \mu \mathrm{m}$. e HSC-4 cells were transfected with control or two different TRPV4 siRNAs (left panel), or were cultured without or with 0.1 and $1 \mu \mathrm{M}$ GSK2193874 (right panel). Cell lysates were probed with anti-phospho-AKT and anti-pan-AKT antibodies. Band intensities were quantified using NIH image software and ratio of phosphoAKT/pan-AKT was expressed as fold-changes compared with control cells. f HSC-4 cells were transfected with control or two different TRPV4 siRNAs and cell lysates were probed with anti-phosphoCaMKII and anti-pan-CaMKII antibodies. Band intensities were quantified using NIH image software and ratio of phospho-CaMKII/ pan-CaMKII was expressed as fold-changes compared with control cells. g HSC-4 cells were cultured without or with $10 \mu \mathrm{M}$ CaMKII inhibitor XII or $10 \mu \mathrm{M}$ Arcyriaflavin A for $24 \mathrm{~h}$. Cell lysates were probed with anti-phospho-AKT and anti-pan-AKT antibodies. Band intensities were quantified using NIH image software and ratio of phospho-AKT/pan-AKT was expressed as fold-changes compared with control cells. h HSC-4 cells were cultured without or with $10 \mu \mathrm{M}$ CaMKII inhibitor XII or $10 \mu \mathrm{M}$ Arcyriaflavin A in the presence of 5\% FBS for the indicated numbers of days, and cell numbers were counted. i HSC-4 cells were cultured without or with $10 \mu \mathrm{M}$ AKT inhibitor VIII in the presence of 5\% FBS for the indicated numbers of days, and cell numbers were counted. Results are shown as means \pm s.d. of three independent experiments. $* P<0.01$.

Consistent with previous reports [30-33], loss-offunction experiments using siRNAs and antagonist revealed that TRPV4 expression and its activation are involved in AKT activation (Fig. 2e and Supplementary Fig. 2e). Intracellular $\mathrm{Ca}^{2+}$ regulates cellular signaling, such as the activation of calmodulin-dependent protein kinase (CaMK) [34], and $\mathrm{Ca}^{2+} /$ calmodulin (CaM) stimulates phosphatidylinositol 3-kinase (PI3K)/AKT [35]. Therefore, we examined the effect of TRPV4 signaling on CaMKII activation in OSCC cells. TRPV4 knockdown reduced CaMKII activation (Fig. 2f and Supplementary Fig. 2f). In addition, experiments using two different CaMKII inhibitors showed that CaMKII activation is involved in AKT activation and cellular growth (Fig. 2g, h and Supplementary Fig. 2g). Furthermore, AKT inhibitor decreased the OSCC proliferative capability (Fig. $2 \mathrm{i}$ and
Supplementary Fig. 2h). Taken together, these results indicate that TRPV4 signaling can regulate CaMKIImediated AKT activation, thereby promoting proliferation in OSCC cells.

To further elucidate the functions of TRPV4, HSC-4 cells expressing mock or TRPV4 were transfected with control or TRPV4 \#1 siRNA. Lentiviral transduction with TRPV4 rescued siRNA-dependent decreases in the TRPV4 protein expression (Fig. 3a). As we used TRPV4 \#1 siRNA that target the 3'-UTR (see Methods), it did not decrease the amount of exogenously expressed TRPV4 in the cells. The effect of TRPV4 \#1 siRNA was confirmed by quantitative RT-PCR using primers encoding the 3'-UTR, which showed that the endogenous TRPV4 mRNA levels were indeed reduced by TRPV4 \#1 siRNA (Fig. 3a). The exogenous TRPV4 expression increased the GSK1016790Adependent $\mathrm{Ca}^{2+}$ influx compared with mock expression (Fig. 3b). In both the cell proliferation assay and migration assay, the exogenous TRPV4 expression rescued the TRPV4-knockdown phenotypes of HSC-4 cells, excluding siRNA off-target effects (Fig. 3c-e). Cells expressing TRPV4 showed similar proliferation capabilities to control cells expressing mock (Fig. 3d). In addition, the TRPV4 expression rescued the TRPV4 knockdown-dependent CaMKII or AKT inactivation but not enhanced endogenous CaMKII or AKT activation (Fig. 3f). GSK1016790A also did not increase the endogenous AKT phosphorylation level (data not shown). These results indicate that the endogenous TRPV4 expression is sufficient to regulate the proliferative ability as well as the CaMKII or AKT activation in HSC-4 cells.

\section{TRPV4 responds to the extracellular environment and regulates cell proliferation}

Based on above results using siRNAs, target sequences of TRPV4 \#1 shRNA were designed to be identical to those of TRPV4 \#1 siRNA and used in the subsequent experiments. HSC-4 cells stably expressing TRPV4 \#1 shRNA were generated to constitutively reduce the levels of endogenous TRPV4 (Fig. 4a). Consistent with our experiments using siRNAs, the GSK1016790A-dependent $\mathrm{Ca}^{2+}$ influx was indeed decreased in these cells (Fig. 4b).

TRPV4 reportedly responds to extracellular stimulations, such as mechanical stress [11-14]. Therefore, we examined whether TRPV4 responds to extracellular culture environments to regulate cellular growth in HSC-4 cells. Constitutive depletion of TRPV4 in HSC-4 cells did not affect their cellular growth on a low-attachment plastic dish but did reduce both the tumor sphere area and the proliferative capability by approximately half in the three-dimensional (3D) culture with Matrigel (Fig. 4c and Supplementary Fig. 3a). These data suggest that TRPV4 expression might 

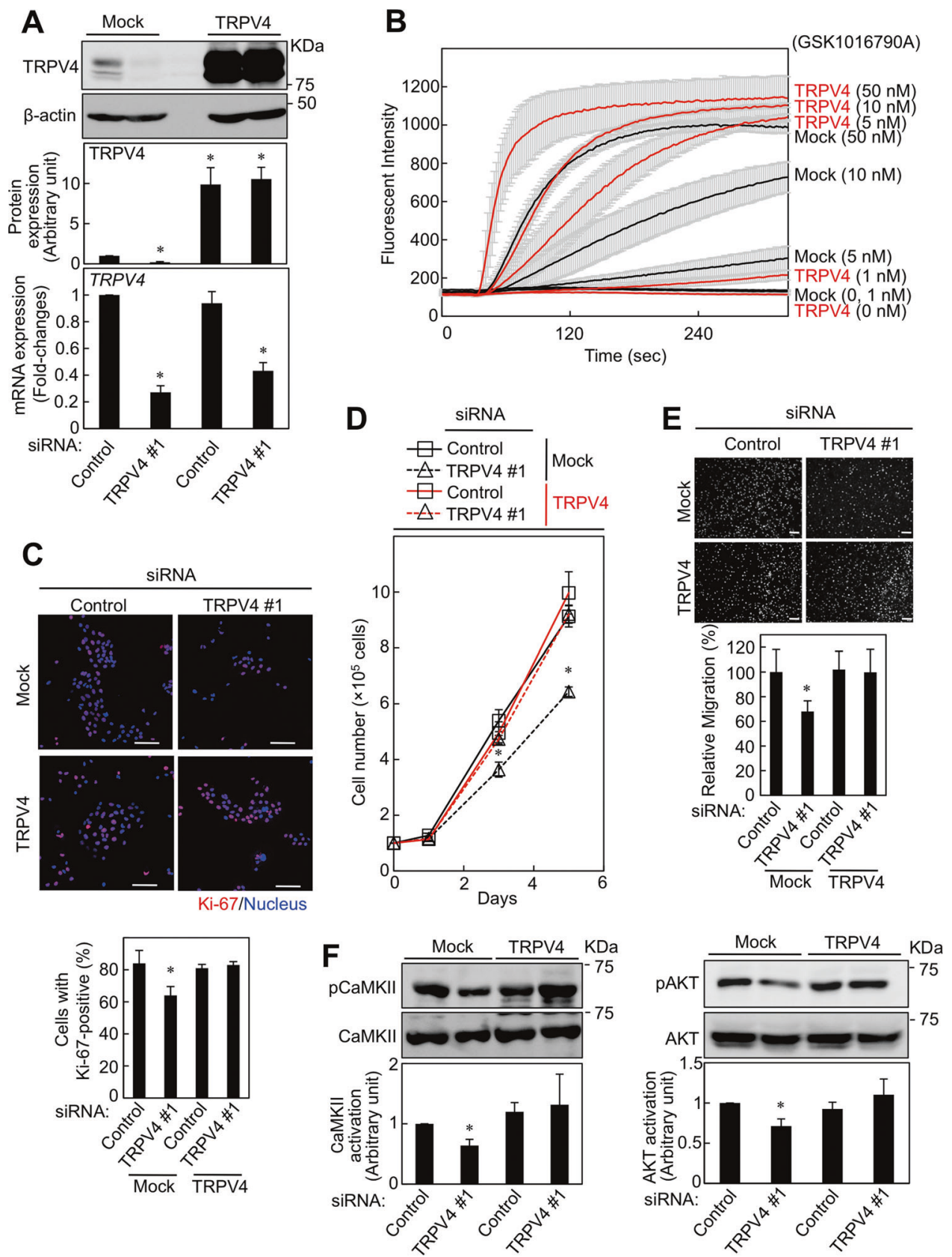

Fig. 3 TRPV4 expression is required for cell proliferation and migration through CaMKII-mediated AKT activation. a HSC-4 cells expressing mock or TRPV4 were transfected with control or TRPV4 \#1 siRNA for $48 \mathrm{~h}$, and cell lysates were probed with anti-TRPV4 and anti- $\beta$-actin antibodies. Band intensities were quantified using NIH image software and ratio of TRPV4/ $\beta$-actin was expressed as fold-changes compared with control cells. Endogenous TRPV4 mRNA levels were measured by quantitative RT-PCR using primers encoding the 3'-UTR. Relative TRPV4 mRNA levels were normalized by GAPDH and expressed as fold-changes compared with levels in mock control siRNA transfected cells. b Fluo-4-AM-loaded HSC-4 cells expressing mock or TRPV4 were cultured in 96-well plates, and were exposed without or with 1, 5, 10, and $50 \mathrm{nM}$ GSK1016790A. Then, intracellular $\mathrm{Ca}^{2+}$ influx was measured. c HSC-4 cells expressing mock or TRPV4 were transfected with control or TRPV4 \#1 siRNA for $48 \mathrm{~h}$. The cells were stained with anti-Ki-67 antibody and Hoechst 33342, and then Ki-67-positive cells and Hoechst 33342-stained cells were counted, respectively. Results are expressed as the percentage of Ki-67-positive cells compared with total Hoechst 33342stained cells. $\times 200$ magnification, scale bars, $100 \mu \mathrm{m}$. d HSC-4 cells expressing mock or TRPV4 were transfected with control or TRPV4 \#1 siRNA were cultured in the presence of 5\% FBS for the indicated numbers of days, and cell numbers were counted. e HSC-4 cells expressing mock or TRPV4 were transfected with control or TRPV4 \#1 siRNA, and then the cells were placed in Transwell chamber for the migration assay. Migration activities are expressed as the percentage of control cells. $\times 100$ magnification, scale bars, $200 \mu \mathrm{m}$. f HSC-4 cells expressing mock or TRPV4 were transfected with control or TRPV4 \#1 siRNA for $48 \mathrm{~h}$. The cell lysates were probed with anti-phospho-CaMKII and anti-pan-CaMKII antibodies (left panel) or anti-phospho-AKT and anti-pan-AKT antibodies (right panel). Band intensities were quantified using NIH image software and ratio of phospho-CaMKII/pan-CaMKII or phospho-AKT/pan-AKT was expressed as fold-changes compared with control cells. Results are shown as means \pm s.d. of three independent experiments. $* P<0.01$. 

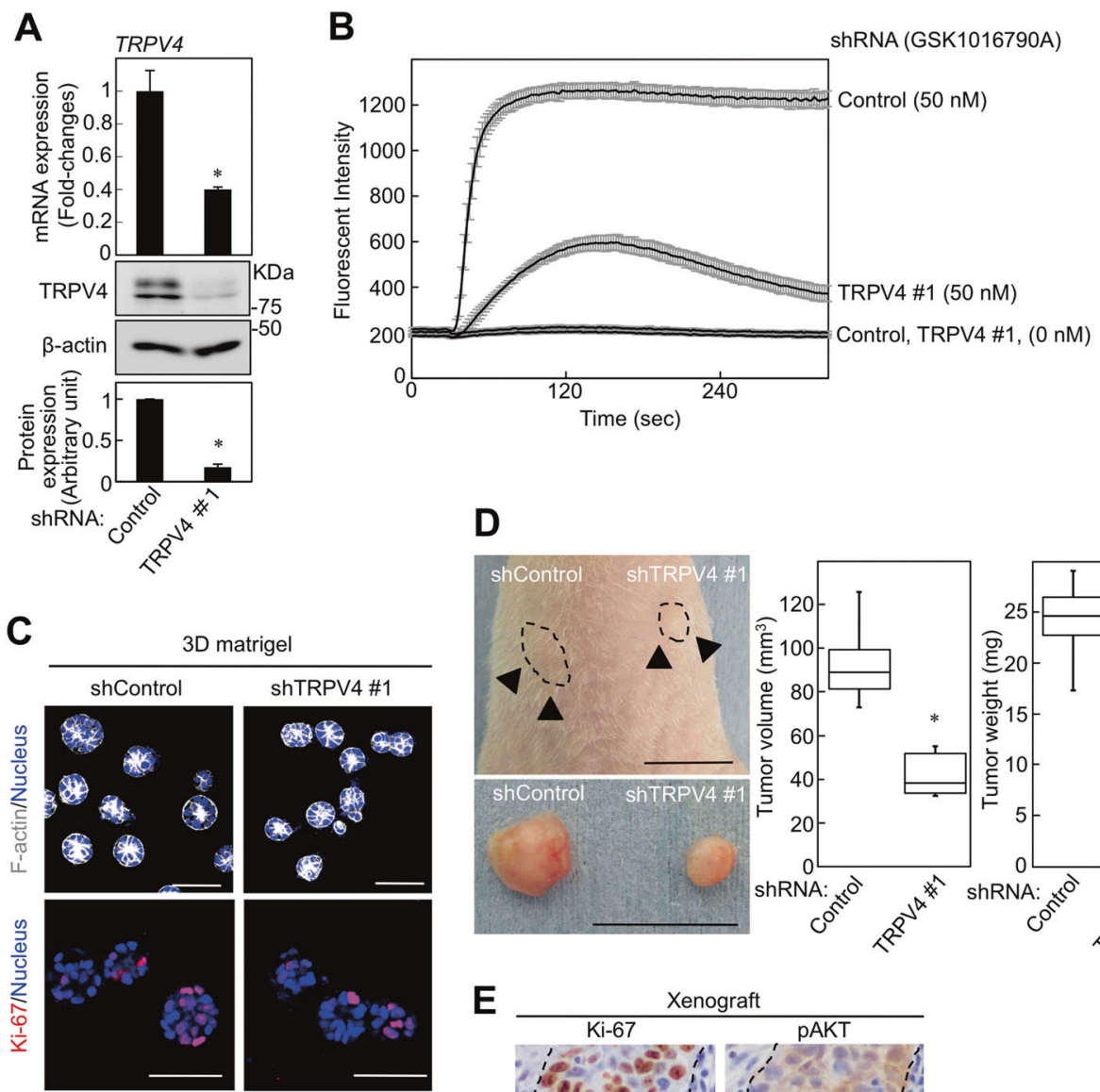

3D matrigel
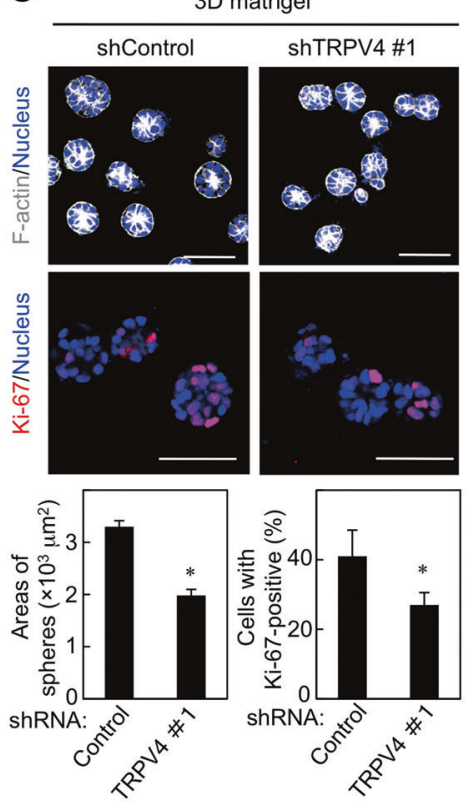

\section{D}
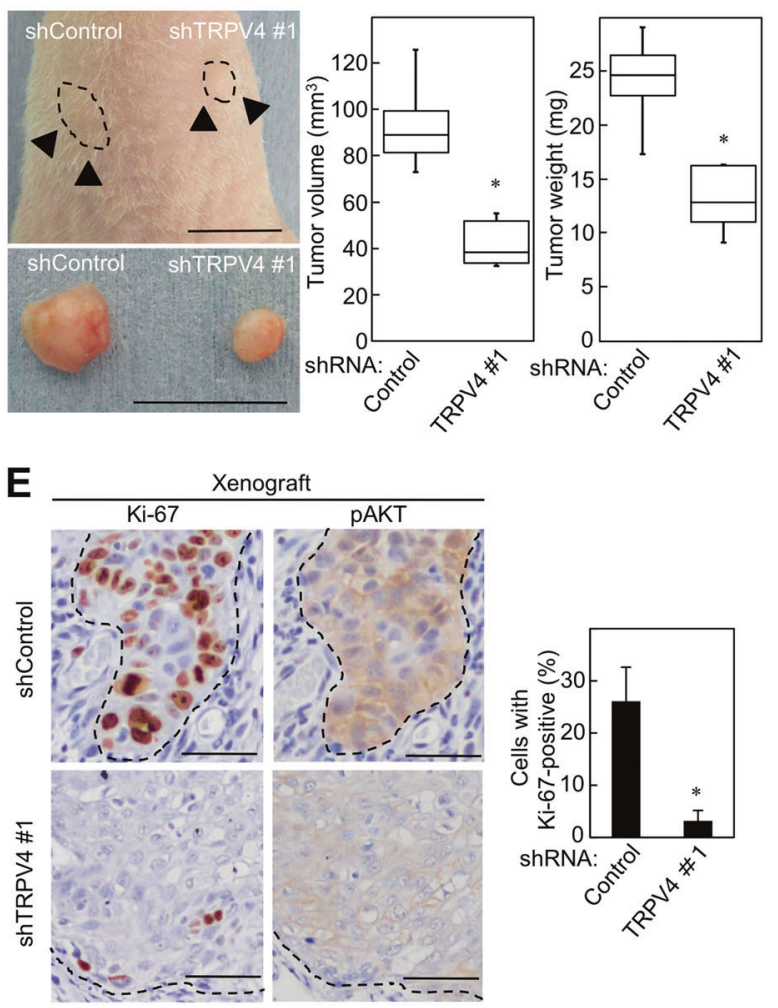

respond to the extracellular environment to regulate the proliferation capability in OSCC cells.

Next, the role of the TRPV4 expression in tumorigenesis in vivo was investigated by subcutaneously implanting tumor cells into the flanks of nude mice. HSC-4 cells stably expressing TRPV4 shRNA demonstrated growth in vivo, but the volumes and weights of the xenograft tumors derived from those cells were less than those of control tumors (Fig. 4d). Immunohistochemical analyses performed on xenografts harvested at the end of the experiment showed that TRPV4 knockdown decreased the numbers of Ki-67-positive cells in tumors; in addition, the AKT phosphorylation levels were also reduced in TRPV4-depleted tumors (Fig. 4e and Supplementary Fig. 3b). These results indicate that the TRPV4 expression is required for tumor formation in vivo.

\section{TRPV4 is expressed in human oral squamous cell carcinoma tissues}

Immunohistochemical analyses were carried out to examine TRPV4 expression in human OSCC specimens. The TRPV4 expression was detected in 22/36 (61.1\%) of tumor lesions, while it was also detected in 6/24 (25\%) of nontumor regions (Fig. 5a). Results were considered positive when the ratio of TRPV4-positive cells was more than $20 \%$ in a tumor lesion or in a non-tumor region. Notably, TRPV4 was strongly expressed in the cell membrane and/or cellular 
4 Fig. 4 TRPV4 responds to extracellular environments and regulates cell proliferation. a Lysates of HSC-4 cells expressing control or TRPV4 \#1 shRNA were probed with anti-TRPV4 and anti- $\beta$-actin antibodies. Band intensities were quantified using NIH image software and ratio of TRPV4/ $\beta$-actin was expressed as fold-changes compared with control cells. b Fluo-4-AM-loaded HSC-4 cells expressing control or TRPV4 \#1 shRNA were cultured in 96-well plates. The cells were exposed without or with $50 \mathrm{nM}$ GSK1016790A, and intracellular $\mathrm{Ca}^{2+}$ influx was measured. c HSC-4 cells expressing control or TRPV4 \#1 shRNA were cultured for 5 days in the 3D Matrigel. The cells were stained with anti-Ki-67 antibody, phalloidin and Hoechst 33342, and then Ki-67-positive cells and Hoechst 33342-stained cells were counted, and areas of spheres were calculated $(n=94)$. Ki-67positive cells were counted, and results are expressed as the percentage of positively stained cells compared with total Hoechst 33342-stained cells $(n=3046) . \times 200$ magnification, scale bars, $100 \mu \mathrm{m}$. d HSC-4 cells $\left(5 \times 10^{7}\right.$ cells $)$ expressing control or TRPV4 \#1 shRNA were subcutaneously implanted into nude mice $(n=6)$. After 14 days, the nude mice were sacrificed. Representative appearance of one mouse (top picture) and extirpated xenograft tumors (bottom picture) are shown. The volumes and weights of the xenograft tumors were measured (right two graphs). Dashed lines show the outline of xenograft tumors, and arrowheads indicate the positions of tumors (top picture). Scale bars, $1 \mathrm{~cm}$. e Sections prepared from xenograft tumors of HSC-4 cells were stained with anti-Ki-67 and anti-phospho-AKT antibodies and hematoxylin. Ki-67-positive cells were counted, and results are expressed as the percentage of positively stained cells compared with total hematoxylin-stained cells $(n=10,977)$ (right graph). Dashed lines show the outline of xenograft tumors. $\times 400$ magnification, scale bars, $50 \mu \mathrm{m}$. Results are shown as means \pm s.d. of three independent experiments. $* P<0.01$.

cytoplasm of the tumor cells, which was invading in the surrounding stroma (Fig. 5a). Based on the intensity of the TRPV4-positive signal, the positive samples were divided into three groups: weak, moderate, and strong (Supplementary Fig. 4a). Both the frequency of TRPV4-positive cases and the intensity of the TRPV4-positive signal tended to be higher in tumor lesions than in non-tumor regions (Fig. 5a). Significant correlations with the degree of TRPV4 intensity and clinical data were not shown for the clinical $\mathrm{T}$ (tumor size) stage, histological grade or lymph node metastasis (Table 1). As reported previously [36, 37], the phosphorylated AKT expression was detected in 14/36 $(38.9 \%)$ of tumor cells, but positive signals were hardly detected in non-tumor regions (Fig. 5b and Supplementary Fig. 4b). Importantly, the phosphorylated AKT expression was more frequently, but not significantly, detected along with TRPV4 expression in consecutive tumor lesion sections (Fig. 5b). These results suggest that the region-specific expression pattern of phosphorylated AKT in tumor lesions tends to merge with the TRPV4 expression in OSCC.

\section{Discussion}

Clinically, it is generally accepted that tumorous ECM is stiffer than adjacent non-tumorous ECM. For example, following transformation, in breast cancer, breast tissue becomes progressively stiffer, and then tumor cells become hyper-responsive to matrix compliance cues, leading to the further activation of $\beta 1$ integrin, FAK and AKT signaling $[38,39]$. Similarly, atomic force microscopy revealed that the stroma of colorectal liver metastasis was stiffer than that of control liver tissue in human pathological specimens as well as in murine liver metastasis models [7]. These reports suggest that matrix stiffening is not only an important tumor feature but also plays a pivotal role in tumor cell behavior. Therefore, cancer research using cell lines needs to be performed in appropriate extracellular environments resembling in vivo situations.

The elastic module of a $2 \mathrm{D}$ plastic dish $\left(2.78 \times 10^{9} \mathrm{~Pa}\right)$, which is conventionally used for cell culture, is markedly higher than that of the normal mammary gland $(167 \pm 31$ $\mathrm{Pa}$ ) or tumor stroma of a mouse breast cancer model $(918 \pm$ $269 \mathrm{~Pa}$ ) [40], suggesting that tumor cells cultured in 2D plastic dishes might differ from in vivo situations. In contrast, the elastic modules of $3 \mathrm{D}$ culture using a reconstituted basement membrane $(175 \pm 37 \mathrm{~Pa})$ or $2.0 \mathrm{mg} / \mathrm{ml}$ collagen $(328 \pm 87 \mathrm{~Pa})$ appear to be similar to the in vivo breast cancer environment [40]. The current study exhibited that constitutive depletion of TRPV4 decreased the OSCC proliferation capability in 3D culture conditions with Matrigel but not in a low-attachment plastic dish. Supporting these results, xenograft models demonstrated that the TRPV4 expression is involved in tumorigenesis. These data indicate that TRPV4 can respond to the extracellular environment, thereby regulating the OSCC cellular growth in vivo. However, the precise mechanism underlying how TRPV4 senses the extracellular environment is unclear.

Previous studies have shown that TRPV4 promotes cancer progression through $\mathrm{Ca}^{2+}$ entry-dependent signaling in gastric cancer [15, 16] and HCC [17], and that TRPV4 overexpression and its signaling correlate with a poor prognosis in breast cancer [32]. In addition, TRPV4 has been reported to activate AKT signaling in the mouse hippocampus [30], endothelial cells [31], breast cancer [32] and glioma cells [33]. Furthermore, stretching mechanical stimulation-induced capillary cell orientation through TRPV4-mediated PI3K activation [41]. Given these present and previous findings, we concluded that TRPV4 might function as an oncogene-related molecule in which TRPV4 activates CaMKII to exert a positive effect on OSCC cell proliferation through AKT signaling.

An immunohistochemical analysis revealed the presence of TRPV4 expression in the tumor lesions as well as in nontumor regions. However, the frequency of TRPV4-positive cases and its signal intensity in the tumor lesions were higher than in the non-tumor regions (see Fig. 5a). These findings therefore suggest that TRPV4 is not a direct molecular target of cancer therapy for preventing side effects in the non-tumor 
Fig. 5 TRPV4 is expressed in human oral squamous cell carcinoma tissues. a Oral squamous cell carcinoma tissues $(n=36)$ were stained with antiTRPV4 antibody and hematoxylin. Percentages of three groups based on TRPV4positive signal intensity in the tumor lesions and the non-tumor regions are shown in the right panel. TRPV4-positive signal intensity is classified as follows: weak; moderate; strong. Dashed box and solid box show enlarged images of non-tumor region and tumor lesion, respectively. $\times 12.5$ magnification, scale bars, $500 \mu \mathrm{m}$. Dashed box and solid box, $\times 400$ magnification. b Oral squamous cell carcinoma tissues $(n=36)$ were stained with antiTRPV4 and anti-phospho-AKT antibodies, and hematoxylin. Solid boxes show enlarged images. $\times 200$ magnification, scale bars, $100 \mu \mathrm{m}$. Solid boxes, $\times 400$ magnification. Numbers of cases with phosphoAKT-positive $(+)$ or phosphoAKT-negative (-), and TRPV4positive (+) or TRPV4-negative $(-)$ were shown.
A

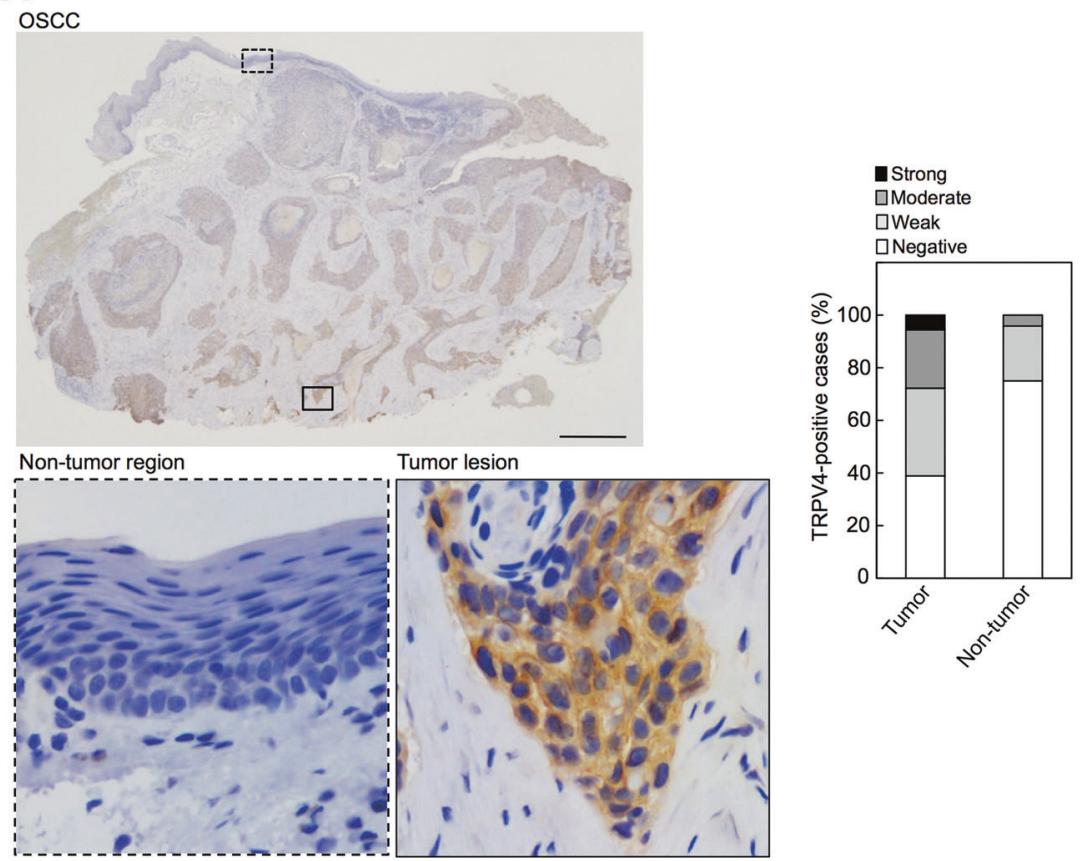

B

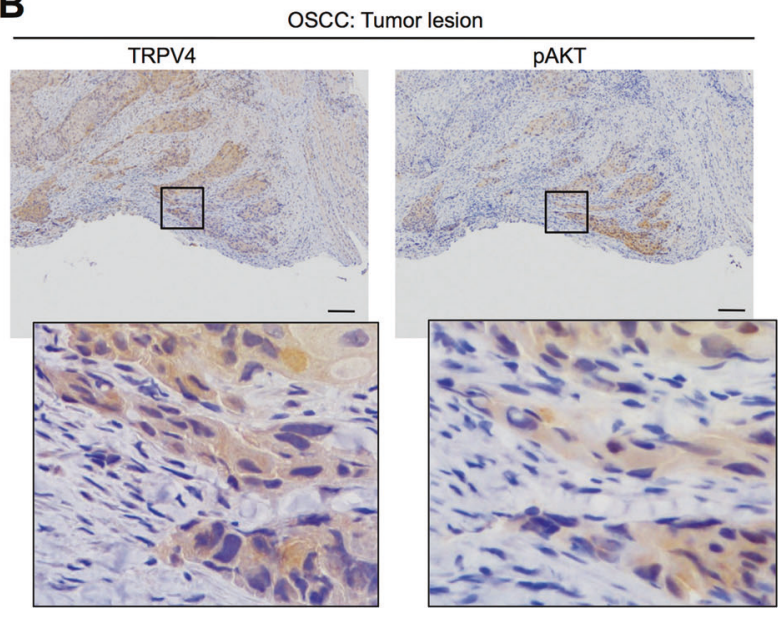

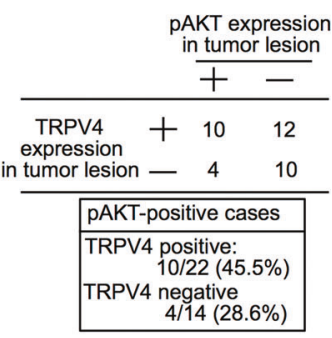

In summary, we found that TRPV4 is highly expressed in several OSCC cell lines and OSCC specimens. We also demonstrated that TRPV4, a $\mathrm{Ca}^{2+}$ channel, responds to the extracellular environment, which in turn inducing CaMKII activity to regulate OSCC cell proliferation through AKT activation both in vitro and in vivo. Taken together, these results suggest that the TRPV4/CaMKII/AKT axis contributes to OSCC tumor cell growth, which might be activated by the tumor extracellular environment.

Acknowledgements The authors thank Mr T. Fujimoto and Dr Y. Mikami for valuable technical support, Dr H. Maeda for forgiving to use P2 room and Dr S. Momosaki for preparing pathological specimens. The authors also thank the Research Support Center, Graduate School of Medical Sciences, Kyushu University. This work was supported by JSPS KAKENHI Grants to SF (2016-2018) (JP16K11501) and SO alytic subunit alpha (PIK3CA) [42]. 
(2016-2018) (16K11738), (2019-2021) (19K10302), and Takeda Science Foundation to SF.

\section{Compliance with ethical standards}

Conflict of interest The authors declare that they have no conflict of interest.

Publisher's note Springer Nature remains neutral with regard to jurisdictional claims in published maps and institutional affiliations.

\section{References}

1. Takata T and Slootweg PJ. Tumours of the oral cavity and mobile tongue. Solan P, Gale N, Hunter K, Lingen M, Nylander K, Reibel J, et al. Malignant surface epithelial tumours. In: El-Naggar AK, Chan JKC, Grandis JR, Takata T, Slootweg PJ, editors. WHO classification of head and neck tumours. 4th ed. Lyon: IARC; 2017. p. 108-111.

2. Warnakulasuriya S. Global epidemiology of oral and oropharyngeal cancer. Oral Oncol. 2009;45:309-16.

3. Sinevici N, O'Sullivan J. Oral cancer: deregulated molecular events and their use as biomarkers. Oral Oncol. 2016;61:12-18.

4. Omar E. Current concepts and future of noninvasive procedures for diagnosing oral squamous cell carcinoma-a systematic review. Head Face Med. 2015;11:6.

5. Humphrey JD, Dufresne ER, Schwartz MA. Mechanotransduction and extracellular matrix homeostasis. Nat Rev Mol Cell Biol. 2014; $15: 802-12$

6. Levental KR, Yu H, Kass L, Lakins JN, Egeblad M, Erler JT, et al. Matrix crosslinking forces tumor progression by enhancing integrin signaling. Cell. 2009;139:891-906.

7. Dou C, Liu Z, Tu K, Zhang H, Chen C, Yaqoob U, et al. P300 Acetyltransferase mediates stiffness-induced activation of hepatic stellate cells into tumor-promoting myofibroblasts. Gastroenterology. 2018;154:2209-.e14.

8. Adapala RK, Thoppil RJ, Ghosh K, Cappelli HC, Dudley AC, Paruchuri S, et al. Activation of mechanosensitive ion channel TRPV4 normalizes tumor vasculature and improves cancer therapy. Oncogene. 2016;35:314-22.

9. Meng Z, Qiu Y, Lin KC, Kumar A, Placone JK, Fang C, et al. RAP2 mediates mechanoresponses of the Hippo pathway. Nature. 2018;560:655-60.

10. Garcia-Elias A, Mrkonjić S, Jung C, Pardo-Pastor C, Vicente R, Valverde MA. The TRPV4 channel. Handb Exp Pharmacol. 2014;222:293-319.

11. Köhler R, Heyken WT, Heinau P, Schubert R, Si H, Kacik M, et al. Evidence for a functional role of endothelial transient receptor potential V4 in shear stress-induced vasodilatation. Arterioscler Thromb Vasc Biol. 2006;26:1495-502.

12. Mendoza SA, Fang J, Gutterman DD, Wilcox DA, Bubolz AH, Li $\mathrm{R}$, et al. TRPV4-mediated endothelial $\mathrm{Ca}^{2+}$ influx and vasodilation in response to shear stress. Am J Physiol Heart Circ Physiol. 2010;298:H466-476.

13. Watanabe H, Vriens J, Suh SH, Benham CD, Droogmans G, Nilius B. Heat-evoked activation of TRPV4 channels in a HEK293 cell expression system and in native mouse aorta endothelial cells. J Biol Chem. 2002;277:47044-51.

14. Liedtke W, Choe Y, Marti-Renom MA, Bell AM, Denis CS, Sali A, et al. Vanilloid receptor-related osmotically activated channel (VR-OAC), a candidate vertebrate osmoreceptor. Cell. 2000;103:525-35.

15. Xie R, Xu J, Xiao Y, Wu J, Wan H, Tang B, et al. Calcium promotes human gastric cancer via a novel coupling of calcium- sensing receptor and TRPV4 channel. Cancer Res. 2017; 77:6499-512.

16. Tang B, Wu J, Zhu MX, Sun X, Liu J, Xie R, et al. VPAC1 couples with TRPV4 channel to promote calcium-dependent gastric cancer progression via a novel autocrine mechanism. Oncogene. 2019;38:3946-61.

17. Fang Y, Liu G, Xie C, Qian K, Lei X, Liu Q, et al. Pharmacological inhibition of TRPV4 channel suppresses malignant biological behavior of hepatocellular carcinoma via modulation of ERK signaling pathway. Biomed Pharmacother. 2018; 101:910-9.

18. Morifuji M, Taniguchi S, Sakai H, Nakabeppu Y, Ohishi M. Differential expression of cytokeratin after orthotopic implantation of newly established human tongue cancer cell lines of defined metastatic ability. Am J Pathol. 2000;156:1317-26.

19. Kibe T, Kishida M, Kamino M, Iijima M, Chen L, Habu M, et al. Immortalization and characterization of normal oral epithelial cells without using HPV and SV40 genes. Oral Sci Int. 2011;8:20-28.

20. Kitsuki T, Yoshimoto RU, Aijima R, Hatakeyama J, Cao AL, Zhang JQ, et al. Enhanced junctional epithelial permeability in TRPV4-deficient mice. J Periodontal Res. 2019;00:1-10. https:// doi.org/10.1111/jre.12685.

21. Matsumoto S, Fujii S, Sato A, Ibuka S, Kagawa Y, Ishii M, et al. A combination of Wnt and growth factor signaling induces Arl4c expression to form epithelial tubular structures. EMBO J. 2014;33:702-18.

22. Mikami Y, Fujii S, Nagata K, Wada H, Hasegawa K, Abe M, et al. GLI-mediated Keratin 17 expression promotes tumor cell growth through the anti-apoptotic function in oral squamous cell carcinomas. J Cancer Res Clin Oncol. 2017;143:1381-93.

23. Takayama Y, Furue H, Tominaga M. 4-isopropylcyclohexanol has potential analgesic effects through the inhibition of anoctamin 1, TRPV1 and TRPA1 channel activities. Sci Rep. 2017;7:43132.

24. Miyoshi H, Blömer U, Takahashi M, Gage FH, Verma IM. Development of a self-inactivating lentivirus vector. J Virol. 1998;72:8150-7.

25. Fujii S, Shinjo K, Matsumoto S, Harada T, Nojima S, Sato S, et al. Epigenetic upregulation of ARL4C, due to DNA hypomethylation in the 3'-untranslated region, promotes tumorigenesis of lung squamous cell carcinoma. Oncotarget. 2016;7:81571-87.

26. Fujii S, Nagata K, Matsumoto S, Kohashi KI, Kikuchi A, Oda Y, et al. Wnt/ $\beta$-catenin signaling, which is activated in odontomas, reduces Sema3A expression to regulate odontogenic epithelial cell proliferation and tooth germ development. Sci Rep. 2019;9:4257.

27. Fujii S, Matsumoto S, Nojima S, Morii E, Kikuchi A. Arl4c expression in colorectal and lung cancers promotes tumorigenesis and may represent a novel therapeutic target. Oncogene. 2015;34:4834-44.

28. Brierley JD, Gospodarowicz MK, Wittekind C. Head and Neck tumors. In: Brierley JD, Gospodarowicz MK, and Wittekind C. editors. TNM classification of malignant tumours. 8th ed. Hoboken, NJ: Wiley Blackwell; 2017. p. 17-21.

29. Mikami Y, Fujii S, Kohashi KI, Yamada Y, Moriyama M, Kawano $\mathrm{S}$, et al. Low-grade myofibroblastic sarcoma arising in the tip of the tongue with intravascular invasion: a case report. Oncol Lett. 2018;16:3889-94.

30. Jie P, Hong Z, Tian Y, Li Y, Lin L, Zhou L, et al. Activation of transient receptor potential vanilloid 4 induces apoptosis in hippocampus through downregulating PI3K/Akt and upregulating p38 MAPK signaling pathways. Cell Death Dis. 2015;6:e1775.

31. Xu S, Liu B, Yin M, Koroleva M, Mastrangelo M, Ture S, et al. A novel TRPV4-specific agonist inhibits monocyte adhesion and atherosclerosis. Oncotarget. 2016;7:37622-35.

32. Lee WH, Choong LY, Jin TH, Mon NN, Chong S, Liew CS, et al. TRPV4 plays a role in breast cancer cell migration via $\mathrm{Ca}^{2+}$ - 
dependent activation of AKT and downregulation of E-cadherin cell cortex protein. Oncogenesis. 2017;6:e338.

33. Ou-Yang Q, Li B, Xu M, Liang H. TRPV4 promotes the migration and invasion of glioma cells via AKT/Rac1 signaling. Biochem Biophys Res Commun. 2018;503:876-81.

34. Takemoto-Kimura S, Suzuki K, Horigane SI, Kamijo S, Inoue M, Sakamoto M, et al. Calmodulin kinases: essential regulators in health and disease. J Neurochem. 2017;141:808-18.

35. Perez-Garcia MJ, Cena V, de Pablo Y, LIovera M, Commella JX, Soler RM. Glial cell line-derived neurotrophic factor increases intracellular calcium concentration. Role of calcium/calmodulin in the activation of the phosphatidylinositol 3-kinase pathway. J Biol Chem. 2004;279:6132-42.

36. Lim J, Kim JH, Paeng JY, Kim MJ, Hong SD, Lee JI, et al. Prognostic value of activated Akt expression in oral squamous cell carcinoma. J Clin Pathol. 2005;58:1199-205.

37. Yu Z, Weinberger PM, Sasaki C, Egleston BL, Speier WF 4th, Haffy B, et al. Phosphorylation of Akt (Ser473) predicts poor clinical outcome in oropharyngeal squamous cell cancer. Cancer Epidemiol Biomarkers Prev. 2007;16:553-8.

38. Butcher DT, Alliston T, Weaver VM. A tense situation: forcing tumour progression. Nat Rev Cancer. 2009;9:108-22.

39. Rubashkin MG, Cassereau L, Bainer R, DuFort CC, Yui Y, Ou G, et al. Force engages vinculin and promotes tumor progression by enhancing PI3K activation of phosphatidylinositol (3,4,5)-triphosphate. Cancer Res. 2014;74:4597-611.

40. Paszek MJ, Zahir N, Johnson KR, Lakins JN, Rozenberg GI, Gefen A, et al. Tensional homeostasis and the malignant phenotype. Cancer Cell. 2005;8:241-54.

41. Thodeti CK, Matthews B, Ravi A, Mammoto A, Ghosh K, Bracha AL, et al. TRPV4 channels mediate cyclic strain-induced endothelial cell reorientation through integrin-to-integrin signaling. Circ Res. 2009;104:1123-30.

42. The Cancer Genome Atlas Network. Comprehensive genomic characterization of head and neck squamous cell carcinomas. Nature. 2015;517:576-82. 